\title{
RANCANG BANGUN MESIN PENGIRIS DAUN BAWANG DENGAN KAPASITAS 300 GRAM PER MENIT
}

\author{
Muhammad Ramadhan ${ }^{1, a}$, Achmad Hatta ${ }^{2, b}$, dan Rodian Situmorang ${ }^{3, c}$ \\ ${ }^{1,2,3}$ Program Studi Teknik Mesin, Politeknik Negeri Bandung, Jl. Gegerkalong Hilir, Ciwaruga, \\ Kabupaten Bandung Barat 40559. Indonesia \\ amuhammad.ramadhan.tme18@polban.ac.id, bachmad.hatta@polban.ac.id
}

\begin{abstract}
Abstrak.
Kebutuhan akan irisan daun bawang relatif banyak, maka dibutuhkan alat yang dapat membantu dalam proses pengirisan yang lebih efektif baik secara tenaga maupun waktu yang dikeluarkan. Berdasarkan permasalahan tersebut tercetuslah ide untuk merancang sebuah mesin pengiris daun bawang guna membantu masyarakat dalam mengiris daun bawang khususnya para penjual makanan yang membutuhkan daun bawang seperti, penjual martabak telur, dan penjual masakan.

Metode yang digunakan adalah studi literatur (kepustakaan), pengamatan lapangan, serta metode penyelesaian masalah berupa rancang bangun yang mencakup pra perencanaan berupa sketsa mesin, perencanaan konsep mesin, perhitungan, pembuatan gambar kerja, pengadaan material dan komponen, pembuatan alat, assembly, serta pengujian.

Luaran projek ini adalah pembuatan mesin pengiris daun bawang yang sederhana dan efektif dengan tidak melupakan faktor keselamatan dan kebersihan sehingga dapat mendukung dalam proses pengirisan daun bawang skala pedagang maupun industri rumahan. Alat ini berkapasitas 300 gram per menit dengan menggunakan motor DC 775 dan bersumber baterai li-ion 18650 sebanyak empat buah.
\end{abstract}

\section{Kata kunci. Rancang Bangun, Pengiris, Daun Bawang}

\begin{abstract}
.
The need for sliced scallions is relatively large, so a tool that can assist in the slicing process is more effective both in terms of energy and time spent. Based on these problems, the idea was born to design a scallion slicing machine to help the community in slicing scallions, especially food sellers who need scallions such as egg martabak sellers, and food sellers.

The method used is literature study (library), field observations, and problem solving methods in the form of design which includes pre-planning in the form of machine sketches, machine concept planning, calculations, making working drawings, procurement of materials and components, tool making, assembly, and testing.

The output of this project is the manufacture of a scallion slicing machine that is simple and effective by not forgetting the safety and hygiene factors so that it can support the slicing process at the scale of traders and home industries. This tool has a capacity of 300 grams per minute using a DC 775 motor and sourced from four 18650 li-ion batteries.
\end{abstract}

Keywords: Design and Fabrication, Slicer, Leeks 


\section{Pendahuluan}

Bawang daun (Allium fistulosum L.) termasuk dalam famili Liliaceae yang berasal dari kawasan dari Asia Tenggara yang kemudian meluas dan ditanam di berbagai wilayah yang beriklim tropis dan subtropis. Sayuran penting ini memiliki banyak kegunaan, bisa dimakan mentah dan dimasak dalam berbagai hidangan. Tanaman muda biasa digunakan untuk resep khusus makanan tertentu.[1] Pada bagian ujungnya, daun bawang berwarna hijau tua, sedangkan batangnya yang berwarna hijau muda atau putih dengan tekstur sedikit keras. Daun bawang juga memiliki aroma dan rasa yang sangat khas, aroma daun bawang yang khas itu membuatnya dijadikan bumbu masak. Meskipun sering dianggap bukan sebagai bumbu dapur utama dan hanya dijadikan bahan pelengkap, namun daun bawang menjadi faktor penting untuk menambah kelezatan rasa masakan. Daun bawang bahkan hampir selalu ada di setiap masakan khas Indonesia.[2] Masakan khas Indonesia yang menggunakan daun bawang sebagai pelezatnya antara lain soto, martabak telur, mie ayam, telur dadar, sop, gorengan dan masih banyak lagi.[2] Penggunaan daun bawang sebagai bumbu masakan biasanya dengan cara dicuci terlebih dahulu lalu diiris kecil kemudian dicampurkan ke dalam masakan. Potongan daun bawang standar dapat digunakan untuk membuat martabak, atau sup yang bentuknya bulat dan tipis.

Pada pengirisan daun bawang secara optimal dengan cara tradisional memiliki keterbatasan, yaitu: jumlah daun bawang yang diiris terbatas, hanya sekepal tangan saja jika dihitung kurang lebih 150 gram saja. Selain itu, dari segi keselamatan harus ekstra berhati hati dikarenakan jika lengah sedikit akan mengakibatkan luka pada tangan. Serta harus fokus pada pengerjaan nya dan tidak bisa ditinggalkan. Lama nya waktu pemotongan dengan cara tradisional sekitar 30-45 detik, sedangkan tenaga yang dihasilkan manusia terbatas. Dari permasalahan yang saya sebutkan tersebut, pembuatan mesin pengiris daun bawang dengan kapasitas 300 gram per menit diharapkan dapat memberikan manfaat dan mempermudah pengerjaan, terutama bagi para pedagang yang menggunakan daun bawang sebagai bahan pelengkap.

\section{Metode Penelitian}

Metode yang penulis gunakan adalah metode penyelesaian masalah dengan sistematika ditunjukkan pada Gambar 1- Diagram Alir Metode Penyelesaian Masalah sebagai berikut :

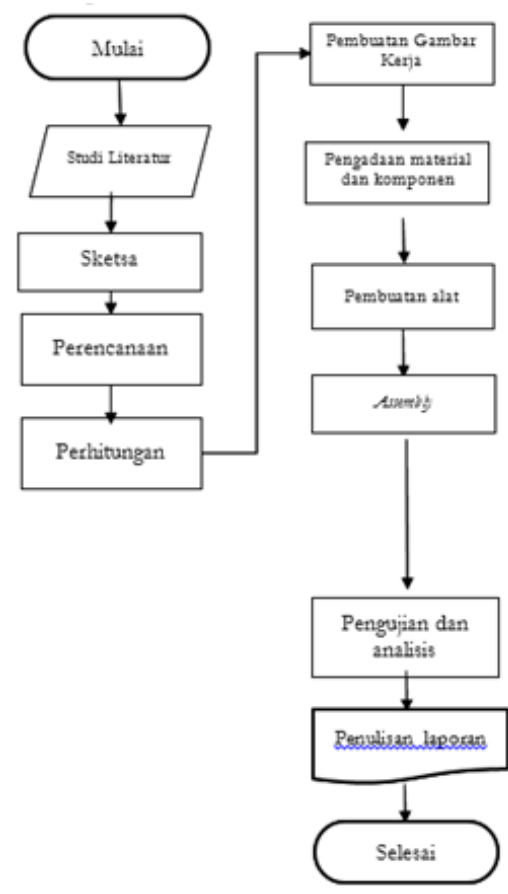


Dalam rancang bangun ini hal yang pertama dilakukan yaitu studi literatur yang merujuk pada teori dan referensi yang berhubungan dengan mesin pengiris daun bawang dengan kapasitas 300 gram per menit. Langkah kedua adalah pra perencanaan melakukan tahap pembuatan sketsa kasar mengenai mesin yang akan dibuat beserta mekanisme nya. Kemudian hasil sketsa tersebut diproses lebih detail pada proses perencanaan.

\section{Proses Perencanaan}

Pada proses perencanaan tahapan yang paling penting adalah melakukan identifikasi masalah, adapun beberapa hal yang penting dalam melakukan identifikasi masalah diantaranya :

1. Menjelaskan fungsi dan cara kerja alat.

2. Melakukan kajian pemilihan komponen dan material.

Hasil dari tahap perencanaan adalah konsep terpilih yang nantinya akan dijadikan sebagai acuan proses pembuatan dan cara kerja alat. Untuk konsep yang terpilihnya yaitu, keluaran dari hasil pengirisan pada mesin pengiris daun bawang ini berbentuk standar dengan diameter menyesuaikan daun bawang serta tebal $3-5 \mathrm{~mm}$.

\section{Proses Perhitungan}

Untuk mengetahui kebutuhan material dan komponen serta menindaklanjuti dari tahap perencanaan, dilakukan perhitungan sebagai berikut:

a) Perhitungan Pemotongan

- Gaya pada pemotong saat dilakukan percobaan dengan cara pemotongan pada daun bawang diatas sebuah neraca tekan lalu dilihat nilai pada saat daun bawang terpotong semuanya, diperoleh nilai sebesar $3.05 \mathrm{kgf}$.

$$
F=3.05 \mathrm{kgf}
$$

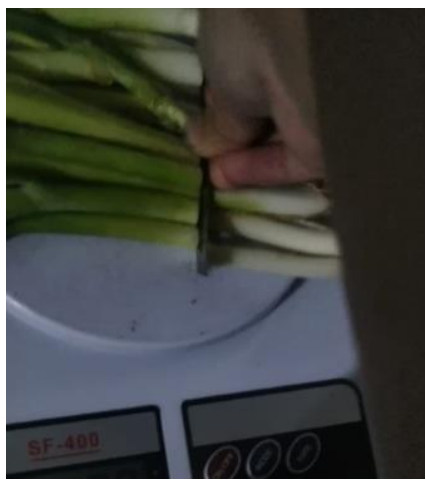

\section{Gambar 2 - Percobaan Pemotongan}

- Torsi pada pisau pengiris daun bawang dengan gaya potong 3.05kgf, dengan jarak pisau dari titik pusat $80 \mathrm{~mm}$, yaitu [3] :

$$
\begin{aligned}
T & =F . r \\
T & =3,05.80 \\
T & =244 \mathrm{kgf} . \mathrm{mm}
\end{aligned}
$$

Dikarenakan menggunakan empat sisi potong nilai torsi dikali empat $T=244 \mathrm{kgf} . \mathrm{mm} \times 4=976 \mathrm{~kg} . \mathrm{mm}$

b) Perhitungan perencanaan putaran mesin (n)

- Kapasitas mesin pemotong (Q)

$$
Q=300 \frac{\mathrm{gram}}{\text { menit }}=\frac{18 \mathrm{~kg}}{j a \mathrm{~m}}
$$


Keterangan:

$300=$ kapasitas yang direncanakan

- Panjang hasil pemotongan yang direncanakan $(L p)$

$$
L p=4 m m
$$

- Jumlah Pisau (Z)

$$
\mathrm{Z}=4 \text { pisau }
$$

- Untuk merencananakan putaran mesin, didapat dengan menghitung terlebih dahulu berapa putaran pisau potong untuk memotong per batang daun bawang dengan rumus:

$$
n s=\frac{L}{\operatorname{lp} \times z}=\frac{610}{4 \times 4}=38,1=38 \text { putaran }
$$

Keterangan:

$\mathrm{L}:$ panjang tertinggi $(\mathrm{mm})$

Lp : panjang pemotongan yang direncanakan $(\mathrm{mm})$

$\mathrm{Z}$ : jumlah pisau

ns : Putaran pisau potong

- Sehingga untuk menghitung putaran mesin yang dibutuhkan sebagai berikut:

$$
\begin{aligned}
& Q=\frac{n}{n s} \cdot w \\
& n=\frac{38 \text { putaran }}{0,034 \times 10} \cdot 18 \frac{\mathrm{kg}}{\text { jam }} \\
& n=2011.8=33,5 \frac{\text { putaran }}{\text { menit }} \\
& =34 \mathrm{rpm}
\end{aligned}
$$

Keterangan:

$0,034 \times 10=$ berat daun bawang per batang $\times 10$ batang daun bawang

Oleh karena itulah dibutuhkan pengontrol kecepatan motor agar dapat diatur hingga 34 rpm.

c) Perencanaan Daya Gerak

- Untuk mengetahui daya dari pemotongan dibutuhkan kecepatan pisau, dapat dicari dengan rumus sebagai berikut [4] :

$$
V=\frac{\pi \cdot d \cdot n}{60 \cdot 100}
$$

Dikarenakan jarak dari sumbu pisau menuju ujung pisau $80 \mathrm{~mm}$ dan menggunakan empat sisi mata pisau, jadi nilai (d) yaitu $32 \mathrm{~cm}$.

$$
\begin{aligned}
V & =\frac{\pi \cdot d \cdot n}{60 \cdot 100} \\
V & =\frac{\pi \cdot 32 \cdot 34}{60 \cdot 100} \\
V & =\frac{\pi \cdot 32 \cdot 34}{60 \cdot 100}=0,57 \mathrm{~m} / \mathrm{s}
\end{aligned}
$$


Keterangan:

$\mathrm{d}=$ jarak dari sumbu pemotong dengan benda yang akan dipotong $(\mathrm{cm})$

$\mathrm{n}=$ putaran yang dibutuhkan (rpm)

$\mathrm{V}=$ Kecepatan pisau $(\mathrm{m} / \mathrm{s})$

$100=$ Konversi $\mathrm{cm} \mathrm{ke} \mathrm{m}$

- Untuk mencari daya yang dibutuhkan dalam pengirisan daun bawang, digunakan rumus sebagai berikut [4] :

$$
\begin{aligned}
& P=f \cdot V \cdot Z \\
& P=3,05 \cdot 0,57 \cdot 4 \\
& P=(3,05 \cdot 9,8) \cdot 0,57 \cdot 4 \\
& P=68,1 \text { watt }
\end{aligned}
$$

Keterangan:

$\mathrm{f}=$ Gaya potong rata rata $(\mathrm{N})$

$\mathrm{V}=$ Kecepatan pisau $(\mathrm{m} / \mathrm{s})$

$\mathrm{Z}=$ Jumlah Mata Pisau

- Faktor Koreksi [5] :

$$
\begin{aligned}
& f c=1,2 \\
& P d=1,2 \cdot P \\
& P d=1,2 \cdot 0,0681=0,08 \mathrm{KW}
\end{aligned}
$$

d) Perencanaan Sambungan Mur Pengunci dan Baut Poros Connector

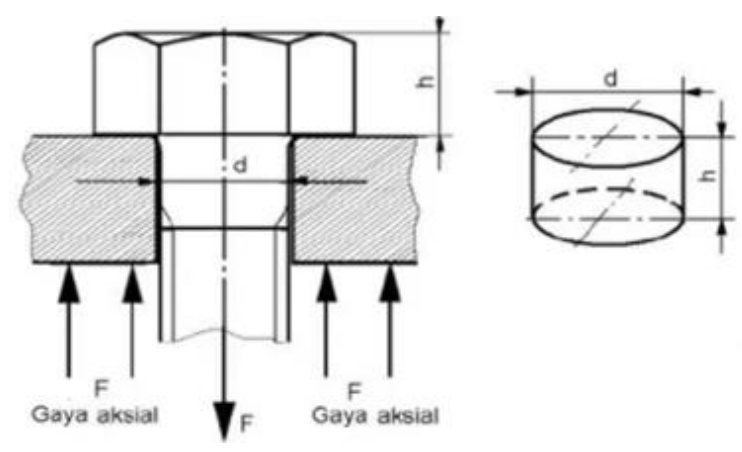

Gambar 3 - Free Body Diagram Mur dan Baut Connector

- Tegangan Tarik pada Baut Connector dan Mur Pengunci M10

Diketahui:

$\tau a=$ tegangan Tarik izin baut $\left(\mathrm{kg} / \mathrm{mm}^{2}\right)$

$\mathrm{W}=$ beban coupler + beban kapasitas daun bawang $=0,3 \mathrm{~kg}$

$\mathrm{d}=$ Diameter nominal ulir $(\mathrm{mm})=10$

$\mathrm{di}=$ diameter inti $(\mathrm{mm})=8,376$

de $=$ Diameter efektif/rata-rata ulir $(\mathrm{mm})=9,026 \mathrm{~mm}$

Data pengunci:

Untuk bahan ulir luar pada pengunci berbahan baja liat, serta ulir dalam berbahan baja liat perunggu dan memiliki nilai yang diizinkan $(\sigma i)$ sebesar $3 \mathrm{~kg} / \mathrm{mm}^{2}$, dikarenakan faktor 
keamanan (v) yang diambil adalah yang bernilai maksimal pada tabel koreksi daya [5] bernilai 2 maka persamaan tegangan tarik izinnya $\left(\sigma t^{\prime}\right)$ sebagai berikut [6] :

$\sigma t^{\prime}=\frac{\tau a 1}{V}=\frac{3}{2}=1.5 \mathrm{~kg} / \mathrm{mm}^{2}$

Diketahui:

$d=10 \mathrm{~mm}$

$d i=8,376 \mathrm{~mm}$

$w=0,3 \mathrm{~kg}$

$\sigma t=\frac{4 \cdot w}{\pi \cdot d i}$

$\sigma t=\frac{4 \cdot 0,3}{\pi \cdot 8,376^{2}}=0,0054 \mathrm{~kg} / \mathrm{mm}^{2}$

Dikarenakan tegangan tarik izin < tegangan tarik maka baut connector dan mur pengunci aman dari tegangan tarik.

- Tegangan Geser Pada Baut Connector dan Mur Pengunci M10

Jenis pembebanan dari ulir adalah pembebanan melintang maka rumus yang digunakan untuk mencari tegangan geser yang diizinkan sebagai berikut [6]:

$\tau g^{\prime}=0,8 \cdot t a$

$\tau g^{\prime}=0,8 \cdot 1,5=1,2 \mathrm{~kg} / \mathrm{mm}^{2}$

Dikarenakan ukuran baut poros connector yang digunakan yaitu M10 dan jumlah mur pengunci yang digunakan (n) berjumlah satu buah, maka tegangan gesernya sebagai berikut [6]:

$$
\begin{aligned}
& \tau g=\frac{4 \cdot f}{\pi \cdot d e^{2} \cdot n} \\
& \tau g=\frac{4.5}{\pi \cdot 9,026^{2} \cdot 1} \\
& =0,078 \mathrm{~kg} / \mathrm{mm}^{2}
\end{aligned}
$$

Dikarenakan tegangan geser izin < tegangan geser maka baut dan mur pengunci aman dari tegangan geser

\section{Pengadaan Komponen dan Material}

Setelah perhitungan selesai, lanjut pada proses pengadaan komponen dan material yang dapat dilihat pada Tabel 2 - Pengelompokan Komponen

Tabel 2 - Pengelompokan Komponen

\begin{tabular}{|r|l|l|}
\hline No & Nama Komponen & Keterangan \\
\hline 1 & Dudukan & Dibuat \\
\hline 2 & Column & Dibuat \\
\hline 3 & Rumah Cutter & Dibuat \\
\hline 4 & Hooper & Dibuat \\
\hline 5 & Pembatas Bagian Atas & Dibuat \\
\hline 6 & Pembatas Bagian Bawah & Dibuat \\
\hline
\end{tabular}




\begin{tabular}{|r|l|l|}
7 & Motor DC 775 & Standar \\
\hline 8 & Bracket 775 & Standar \\
\hline 9 & Coupler & Standar \\
\hline 10 & Pisau & Dibuat \\
\hline 11 & Box Baterai & Standar \\
\hline 12 & Speed Control PWM & Standar \\
\hline 13 & Baterai Li-Ion 18650 & Standar \\
\hline 14 & Pengunci & Standar \\
\hline 15 & Mur dan Baut & Standar \\
\hline 16 & Engsel & Standar \\
\hline 17 & Push Button & Standar \\
\hline
\end{tabular}

Pada material yang digunakan untuk komponen yang dibuat, dipilih berdasarkan obyek yang akan diiris, yaitu daun bawang. Maka, materialnya pun menggunakan material dengan standar food grade, yaitu stainless steel 304 .

Tahap selanjutnya yaitu tahap pembuatan, tahap yang merealisasikan hal yang sudah dirancang sebelumnya, untuk dijadikan sebuah mesin. Hal yang harus diperhatikan dalam tahap ini adalah pembuatan part sesuai dengan rancangan dan gambar kerja.

Selanjutnya jika semua komponen yang dibutuhkan sudah tersedia, maka dilakukanlah penyatuan atau assembly. Penyatuan komponen pada bagian yang menggunakan stainless steel 304 menggunakan spot welding, dikarenakan mempertimbangkan aspek kemudahan serta ketebalan pada komponen. Lakukan pemasangan dengan teliti, sesuai dengan rancangan dan gambar kerja, tidak boleh ada tahap yang tidak sesuai dan terlewatkan.

\section{Hasil dan Pembahasan}

Pada bagian ini menjelaskan hasil dari rancang bangun mesin pengiris daun bawang dengan kapasitas 300 gram.

\section{- Hasil Perakitan}

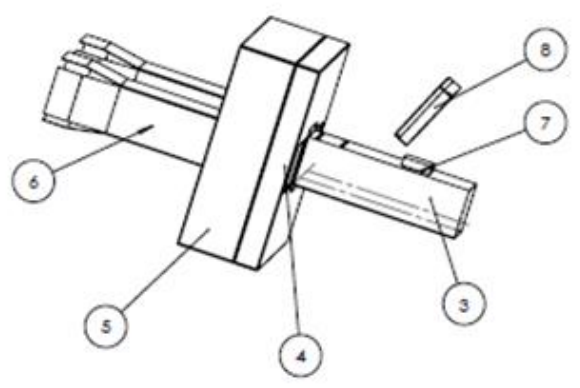

\begin{tabular}{|c|c|c|c|c|}
\hline Push Button On-Off & $s$ & Plastic & saxpmm & stondor \\
\hline Box Baterai & 7 & Plastic & nowams & stancor \\
\hline Hooper & 6 & 55304 & Lavar isoms= & Dibuar \\
\hline Ruman Cutrer Atos & $s$ & 55304 & $20020000 \mathrm{n}$ & Dibuat \\
\hline Ruman Cutrer Bowan & 4 & sssod & 200:asosand & Dibuat \\
\hline column & 3 & 55304 & cowarisoment & Dibuat \\
\hline
\end{tabular}

Gambar 4 - Desain Mesin Pengiris Daun Bawang 


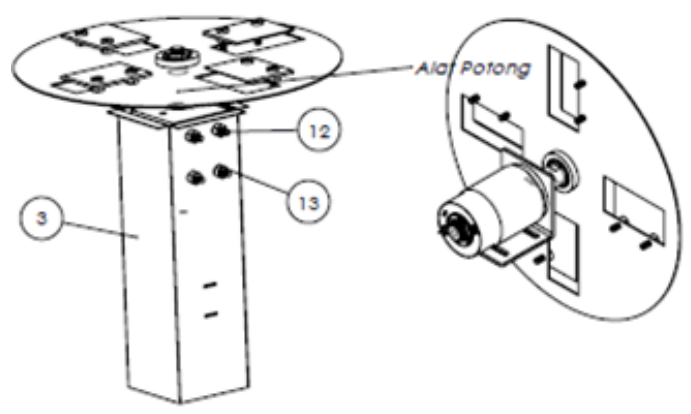

\begin{tabular}{|c|c|c|c|c|c|}
\hline 2 & Bout & 13 & steel & Mat & Standor \\
\hline 2 & Mur & 12 & Steel & Mat & Standor \\
\hline & column & 3 & 55304 & sorsoconar al & Dibuat \\
\hline
\end{tabular}

Gambar 5 - Sub Assy Column

\section{- Hasil Akhir Mesin}

Bentuk dan prinsip kerja dari mesin terdapat perubahan yang awalnya berposisi vertikal menjadi horizontal, dan pada komponen nya terdapat perubahan pada bagian pisau serta pengurangan pada bagian dudukan atas dan bawah yang diganti dengan alat bantu pada Gambar 7-Alat Bantu Mesin yang berfungsi sebagai dudukan dari mesin yang bertujuan menahan mesin agar tetap stabil, dikarenakan rpm yang cukup tinggi, yaitu $\pm 5000 \mathrm{rpm}$.

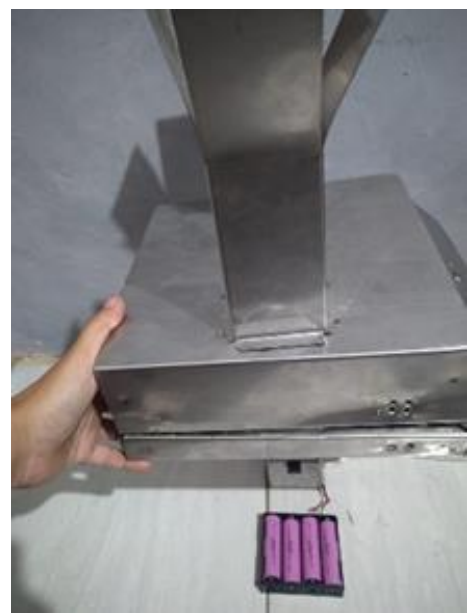

Gambar 6 -Hasil Akhir Mesin Pada Posisi Vertikal 


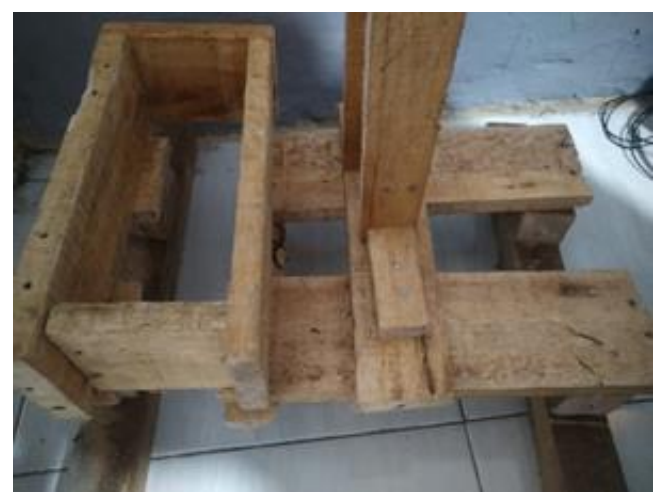

Gambar 7 - Alat Bantu Mesin

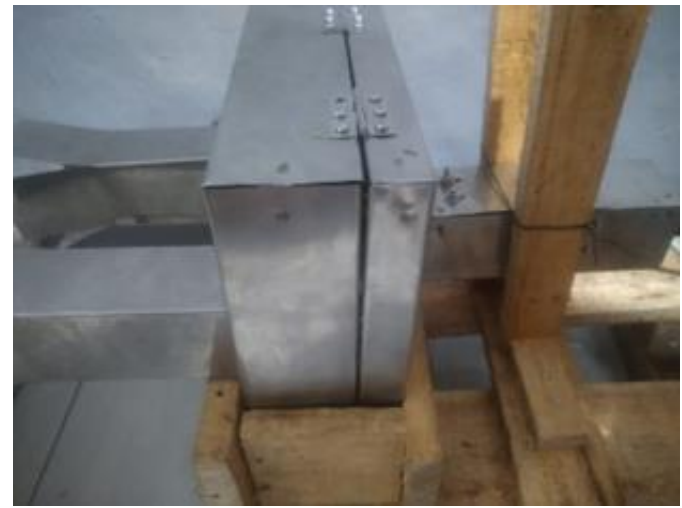

Gambar 8 - Posisi Akhir Mesin

\section{- Pembahasan}

Mesin ini digerakan dengan sumber yang digunakan baterai, yang memiliki spesifikasi output $14.8 \mathrm{~V}$, dan arus $3 \mathrm{~A}$, serta motor yang digunakan memiliki spesifikasi arus $2.9 \mathrm{~A}$ dan input $12-24 \mathrm{~V}$, maka pengontrol kecepatan yang dibutuhkan harus memiliki spesifikasi arus yang diatas $3 \mathrm{~A}$, serta input dan output $0-24 \mathrm{~V}$

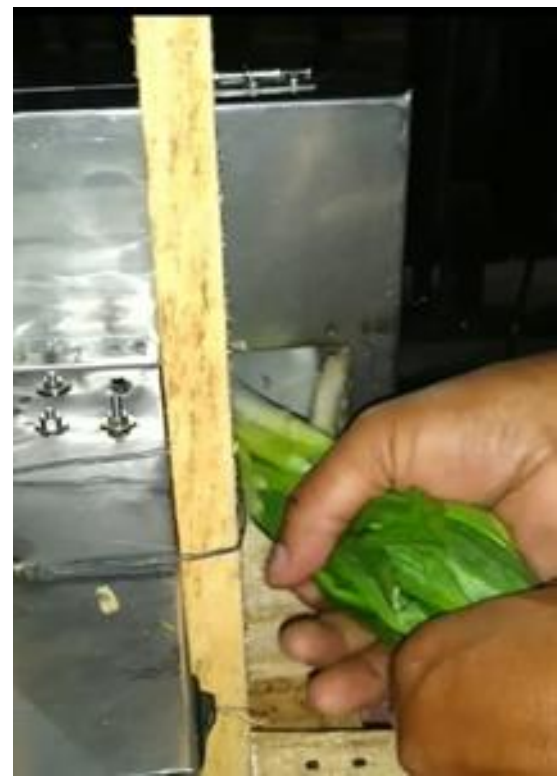

\section{Gambar 9 - Pengujian Mesin}

Pada saat pengujian, mesin dapat dioperasikan dengan kapasitas 300 gram per menit dengan hasil pengirisan yang tidak beraturan pada bentuknya seperti pada Gambar 11 - Hasil Pengirisan Dengan 
Menggunakan Mesin. Hal itu disebabkan karna rpm yang terlalu tinggi sebesar $\pm 5000 \mathrm{rpm}$ dan tidak ada pengontrol kecepatan

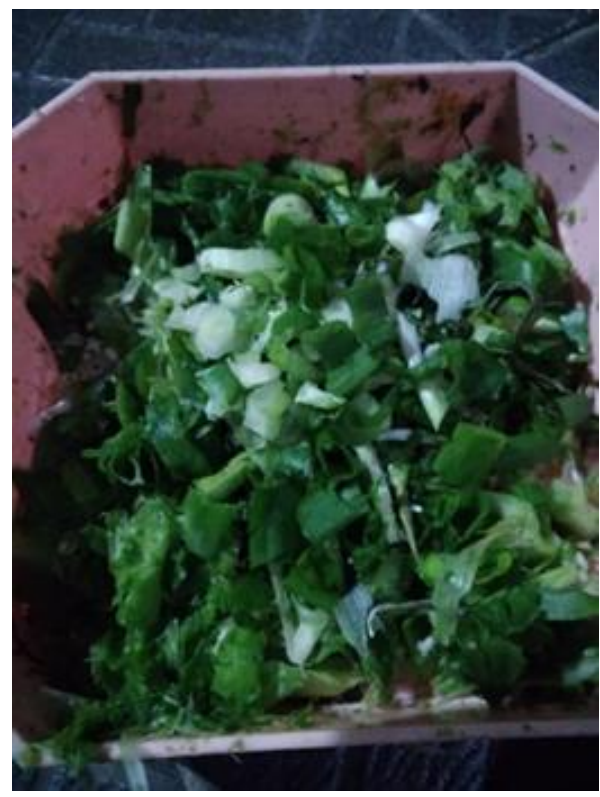

\section{Gambar 10 - Hasil Pengirisan Daun Bawang Menggunakan Mesin}

Perubahan dari hasil pengirisan, prinsip kerja, dan bentuk dari komponen disebabkan oleh rpm yang terlalu tinggi sebesar $\pm 5000 \mathrm{rpm}$ dan tidak ada pengontrol kecepatan. Sehingga bagian komponen harus menyesuaikan. Pengontrol yang sesuai dengan yang dibutuhkan yaitu arus listrik lebih dari 3A, serta input dan output 0-24 V, sehingga mesin dapat dikendalikan baik kecepatan putarannya maupun hasil pengirisannya.

\section{Kesimpulan dan Saran}

Dari rancang bangun mesin tersebut didapat kesimpulan sebagai berikut:

Pada saat pengujian hasil mesin tidak berfungsi secara optimum, tetapi ada beberapa hal yang didapat dari hasil perancangan tersebut.

1. Dapat mengiris daun bawang, walaupun ketebalannya tidak sesuai rencana.

2. Pengirisan daun bawang lebih banyak dibandingkan dengan cara konvensional.

Adapun saran dari penulis adalah:

1. Mangkuk yang disiapkan untuk mewadahi daun bawang yang sudah dipotong berbentuk secukupnya, menyesuaikan dengan dudukan atau alat bantu, serta jangkauan jatuhnya hasil potong daun bawang.

2. Gunakan pengatur kecepatan dengan arus lebih besar dari 3A serta input dan output 0-24V, agar hasil pengirisan dari daun bawang sesuai perencanaan.

3. Obyek yang akan diolah atau diiris, berbentuk dan berkapasitas secukupnya menyesuaikan dengan ukuran hooper.

4. Hindari memasukan tangan atau rambut pada hooper saat mesin beroperasi.

5. Gunakan alat bantu seperti pada Gambar IV-6 Posisi Akhir Mesin jika kecepatan masih diatas $1000 \mathrm{rpm}$. 


\section{Referensi}

[1] NN. "II Tinjauan Pustaka,” 2011. http://eprints.mercubuana-yogya.ac.id/3904/3/bab\%20II.pdf. Diakses pada 28 Februari 2021.

[2] Dahayu,Ria. "Daun Bawang, Pengertian dan Manfaat," 2018. https://sahabatdapur.com/artikel/daun-bawang-pengertian-dan-manfaat/. Diakses pada 28 Februari 2021.

[3] Kanginan, Marthen.2002. Fisika Untuk SMA Kelas XI Semester 2. Erlangga.

[4] Rusdiyana,Liza,dkk. 2014. Analisa Gaya dan Daya Mesin Pencacah Rumput Gajah Berkapasitas 1350 kg/jam.Jurnal Energi dan Manufaktur. (7)2: 119-224.

[5] Sularso, Kiyokatsu,Suga.1997. Dasar Perancanaan dan Pemilihan Elemen Mesin. Jakarta: PT.Pradnya Paramita.

[6] NN.(TT). "Mencari tegangan geser pada sambungan ulir di poros bawah dan belakang".https://swingwheel.wordpress.com/perhitungan-komponen/perhitungan-kekuatanulir/mencari-tegangan-geser-pada-baut-dan-mur/mencari-tegangan-geser-pada-sambunganulir-di-poros-bawah-dan-belakang/. Diakses pada 2 Agustus 2021. 